Int. J. Electrochem. Sci., 15 (2020) 977 - 989

International Journal of

ELECTROCHEMICAL

SCIENCE

WWW.electrochemsci.org

\title{
Selective Preconcentration of Ultra Trace Copper (II) ion Using Square Wave Cathodic Adsorptive Stripping Voltammetry at Modified Carbon Past Electrode
}

\author{
Awad A. Al-rashdi ${ }^{1}$, Ahmed A. Gahlan ${ }^{2}$ and Othman. A. Farghaly ${ }^{2}$ \\ ${ }^{1}$ Umm Al-Qura University, Al-Qunfudah University College, Chemistry Department, Al-Qunfudah \\ Center for Scientific Research (QCSR), Saudi Arabia. \\ ${ }^{2}$ Chemistry Department, Faculty of Science, Al-Azhar University, Assiut branch, 71524, Assiut, \\ Egypt. \\ *E-mail: aarashdi@uqu.edu.sa
}

doi: $10.20964 / 2020.01 .83$

Received: 1 September 2019 / Accepted: 7 November 2019 / Published: 30 November 2019

\begin{abstract}
Ultra-trace copper determination in natural water and human hair samples was performed using stripping voltammetric based on Square wave cathodic adsorptive. The mechanism of Square wave cathodic Adsorptive Stripping was applied to increase the sensitivity of the proposed method. Copper (II) was preconcentrated on the surface of the carbon past electrode modified by pa(E)-2-(Mercaptophenylamino-methylene)-3-oxo-N-p-tolyl-butanamide (MPMPB) through a surface coordination effect. To optimize the analysis of copper(II) ion, different parameters such as $\mathrm{pH}$, accumulation potential and time, medium, scan rate, and ionic strength were investigated. By applying the optimal conditions, the adsorbed form is reduced irreversible viz; $0.1 \mathrm{M}$ Britton-Robinson at $(\mathrm{pH} \sim 6.00)$ with linear concentration ranges of $0.013-0.064$ at 15,30 and $0.012-0.076 \mathrm{ng} / \mathrm{mL}$ at $60 \mathrm{~s}$. The common electroactive and metal ions interferences were tested. To increase the selectivity of the proposed method, common interferences of electroactive and metal ions were studied. This method is sensitive selective, and efficient, therefore it can determine the low levels of copper(II) in water and human hair samples successfully.
\end{abstract}

Keywords: square wave adsorptive stripping voltammetry, ultra trace determination of copper, carbon paste electrode modified by (MPMPB), surface water, human hair samples.

\section{$\underline{\text { FULL TEXT }}$}

(C) 2020 The Authors. Published by ESG (www.electrochemsci.org). This article is an open access article distributed under the terms and conditions of the Creative Commons Attribution license (http://creativecommons.org/licenses/by/4.0/). 